\title{
Comparison of variation of intraocular pressure in noncontact tonometry in patients subjected to phacoemulsification and trabeculectomy with phacoemulsification
}

This article was published in the following Dove Press journal:

Clinical Ophthalmology

\section{Francisco Wellington \\ Rodrigues' \\ Henrique Ferreira Pucci \\ Lucas Oliveira Cintra ${ }^{2}$ \\ Rodrigo Egídio da Silva' \\ 'VER Excellence in Ophthalmology, Goiânia, Goiás, Brazil; ${ }^{2}$ Department of Ophthalmology, Pontifícia Universidade Católica de Goiás, Goiânia, Goiás, Brazil}

\begin{abstract}
Objective: Evaluate the pattern of intraocular pressure (IOP) variations through the pneumatic tonometer, between two specific surgical techniques, and the possible variables that may influence the behavior of this pressure.

Methods: Retrospective cross-sectional study carried out through the review of electronic medical records of a private ophthalmological reference hospital in the city of Goiânia, Goiás, Brazil, from 2012 to 2016, comprising of a sample of 550 eyes. The analyzed variables were, age, gender, IOP, axis, pachymetry, anterior chamber depth, and axial length.

Results: In the end, the study consisted of 231 eyes, represented by 179 patients. Of these, 182 eyes were operated on by isolated cataract surgery, with a mean age of $72.0 \pm 9.5$ years. The combined surgery represented a total of 49 eyes, 34 patients with a mean age of $71.9 \pm 8.14$ years. There was statistical significance $(P<0.05)$ in correlating the pre- and postoperative IOP values in the 24-hour, 7-, 15-day, and 12-month postoperative periods.

Conclusion: A standard of variation of IOP was found through the pneumatic tonometer in both surgical techniques, but a more significant reduction was observed in combined surgery than in isolated cataract surgery, and further studies with a greater epidemiological impact are required for confirmation of this conclusion.
\end{abstract}

Keywords: intraocular pressure, pneumatic tonometer, cataract, glaucoma

\section{Introduction}

Cataracts and glaucoma are the leading causes of visual impairment around the world. A cataract consists of any degree of opacity of the lens, not necessarily causing blindness. ${ }^{1}$ Glaucoma, in turn, is a chronic and progressive optic neuropathy, which has characteristic morphological alterations of the optic nerve and retinal nerve fiber layer, resulting in the death of retinal ganglion cells and loss of visual field. ${ }^{2}$ In the world, of the 45 million existing blind people, $40 \%$ is due to cataracts. ${ }^{3}$ According to the World Health Organization, ${ }^{4}$ the annual incidence of this disease is estimated at $0.3 \%$, of which about 550,000 new cases per year are seen in Brazil, thus leading to it being characterized as a public health problem. ${ }^{5,6}$ In 2013, glaucoma cases totaled 64.3 million, with a worldwide prevalence of $3.54 \%$ (3.05\% open angle and $0.5 \%$ closed angle). Of these, $60 \%$ were in Asia, where primary angle-closure glaucoma (PACG) predominates and, second, in Africa, with $13 \%$, with primary open-angle glaucoma (POAG) predominating. About 76 million cases are expected in 2020 and, in 2040, 111.8 million. PACG is less prevalent; however, the number of blind people due to this
Correspondence: Rodrigo Egídio da Silva VER Excellence in Ophthalmology,

Al Americano do Brasil No 260,

Setor Marista, Goiânia, Goiás

74.180-010, Brazil

Tel/fax +55 6230969696

Email rodrigoegidio@ver.med.br 
pathology is similar to POAG (3.9 vs 4.5 million individuals), demonstrating their degree of aggressiveness. ${ }^{7}$

A cataract may be of congenital origin, as in intrauterine, or may be due to acquired infections, senility, trauma, endocrine disorders, among others. ${ }^{1,8}$ The diagnosis is given in cases of reduction of visual acuity and alteration of the crystalline transparency, observed through biomicroscopy. ${ }^{8}$ Treatment is eminently surgical through the facectomy, using the most common technique called phacoemulsification. It is a noninvasive procedure, which leads to a rapid recovery. In addition, the exposure of the conjunctiva without fibrotic processes due to the absence of manipulation of the conjunctiva improves the postoperative result of the filtering surgeries and it contributes to reduce intraocular pressure (IOP). ${ }^{9,10}$

In glaucoma, IOP is increased most of the time; however, it is not an obligatory condition, and there may be optic nerve damage and visual complaints with an IOP within a range considered normal for most people. Also, an increased IOP in relation to the mean of the population and with the patient not presenting any optic nerve damage, in this case, is classified as ocular hypertension. ${ }^{11}$ Thus, ocular hypertension is the main risk factor that can lead to optic nerve damage, resulting in loss of visual field. ${ }^{12}$ The control of IOP is fundamental for a good prognosis of the disease. Its treatment can be both pharmacological and surgical. Traditionally, the main reasons for the surgical choice in glaucoma are the failure of the medication in the control of pressure and the deterioration of the visual field. ${ }^{13}$ Trabeculectomy is the most performed surgery and is intended to prevent the progression of glaucomatous damage by lowering IOP. In this way, the target IOP, with a reduction of more than $30 \%$ of the IOP-base value, may be beneficial for the reduction of the progression of the field defect. ${ }^{14}$ This surgery consists of the creation of a fistula that allows the drainage of the aqueous humor to a pouch formed between the sclera and its lining tissue, promoting the reabsorption of the aqueous humor by the sclera itself. ${ }^{15}$

The coexistence of cataract and glaucoma is a common reality of the elderly; taking into consideration these patients' scenario, combined surgery becomes an interesting option. This surgery is nothing more than the association of phacoemulsification with trabeculectomy, with one or two incisions. In this study, surgery was performed in combination with two incision sites, one for cataract and one for trabeculectomy.

In the single incision, the fistula is created first, and then cataract surgery is performed. In the second approach, phacoemulsification is initially performed, followed by conventional trabeculectomy. ${ }^{16}$ Phacoemulsification combined with trabeculectomy produces better IOP control, with fewer complications than manual cataract extraction. However, in combined surgery, reduction of IOP and its subsequent control are lower when compared to isolated trabeculectomy, probably due to a longer rupture of the bloodocular barrier associated with cataract surgery. ${ }^{17,18}$ Combined surgery has the advantage of intervening in two eye pathologies in one approach, but on the other hand, it is associated with a greater number of complications. In a study by Tham et al, ${ }^{19}$ who compared two groups, one with cataract surgery alone and the other with phacotrabeculectomy in patients with closed-angle glaucoma, no difference in visual acuity and progression of glaucoma between the two was observed.

The tonometer is the device used to perform ocular pressure monitoring. There are several models currently available; however, the most used are the noncontact pneumatic and the Goldmann applanation, with contact, the latter being considered the gold standard for IOP measurement. The pneumatic tonometer has a mechanism to produce a jet of air leading to corneal applanation, in which a beam of light is projected in of which only the reflected and parallel coaxial rays are picked up by the receiver of the apparatus, obtaining a maximum peak of luminous reception when the cornea is flattened. ${ }^{20}$ This device was first used in 1973 by Forbes, and today it is widespread because of its operational advantages: it does not require the use of eye drops, it can be operated by nonmedical professionals, it offers a low risk of contamination, and it is useful in screening programs. ${ }^{21}$ However, Britt et $\mathrm{al}^{22}$ demonstrated the existence of lachrymal film dehiscence and formation of microaerosol with the air blow, which would make the pneumatic tonometer not as aseptic as one imagined. It was also observed that in noncontact tonometry, lower values of IOP were found in the first measurement when compared to subsequent measurements; correlating this fact with a patient's anxiety and corneal factors, such as thickness and curvature, leads to alteration of the results of IOP measurement in both the pneumatic tonometer and the Goldmann applanation. ${ }^{23}$

Due to a small amount of data in the literature, regarding the behavior of IOP between two highly complex surgical techniques when measuring pneumatic tonometry, this study was requested to complement this lacuna. In this way, comparative future studies can be developed in different ethnicities and the creation or perfection of IOP measurement technologies can be quick, safe, and minimally invasive.

The objective of this study was to evaluate the behavior of IOP variation, through the pneumatic tonometer, between 
two specific surgical techniques. With this, it becomes an important supporting instrument for the monitoring of postoperative IOP, due to the practicality in measurement.

\section{Methods}

A retrospective and cross-sectional study was carried out by reviewing electronic medical records from the database of a private ophthalmological reference hospital in the city of Goiânia, Goiás, Brazil, from 2012 to 2016. The present study followed the guidelines of the Declaration of Helsinki and was submitted and approved by the ethics in research commission (CEP) of the Pontifical Catholic University of Goiás (PUC-GO) (number CAAE: 72407517.2.0000.0037). The CEP did not require the informed consent of the patients because it was a review of medical records and the methodology used was not for a prospective study, but a retrospective one. The data collection used the electronic medical record number, and the personal identification of the patients was only known to the doctor responsible for the surgeries. The data with the personal identification remained in the hospital (and did not come into contact with third parties) where the samples were collected.

The study evaluated 550 eyes, and the variables analyzed were age, gender, intraocular pressure, axis, pachymetry, anterior chamber depth (ACD), and axial length.

The IOP was measured and quantified using the Topcon Computerized Tonometer CT-80 pneumatic tonometer or noncontact tonometry (NCT). Their values were recorded as follows: IOP before surgery (last preoperative evaluation), 24 hours, 7, 15, and 30 days, and 3, 6, and 12 months postoperatively.

The inclusion criteria for cataract patients were as follows: patients with cataracts and those over 18 years of age with IOP of $<21 \mathrm{mmHg}$, without perioperative complications, subjected to phacoemulsification by the same surgeon, and absence of ophthalmologic surgeries and/or other ocular previous diseases. In the individuals with glaucoma and cataract, inclusion criteria were cataract present and over 18 years, IOP greater or less than $21 \mathrm{mmHg}$, using at least two classes of antiglaucomatous medication, excavations larger than 0.7 with loss of neuroretinal rim, ${ }^{24}$ open angle with confirmation via gonioscopy, loss of visual field using the Anderson criteria $^{25}$ with minimal reproducibility of at least two visual fields, and/or progression. ${ }^{24-26}$ The exclusion criteria were as follows: patients under 18 years of age, incomplete data in electronic medical records, patients with perioperative or postoperative complications, contact lens users, and/or those with previous ophthalmologic surgeries.
Surgical methods: All surgeries were performed by the same surgeon. Cataract surgeries were performed with topical anesthesia followed by a $3.2 \mathrm{~mm}$ incision in the transparent cornea. In the anterior chamber (AC), a viscoelastic agent was injected and then capsulorhexis was performed. After capsulorhexis, the core was separated with the cortex through balanced salt solution. The separation of the cortex and the lens nucleus were both removed by phacoemulsification. Viscoelastic was placed in the capsular bag for intraocular lens implantation. After implantation of the IOL the viscoelastic agent was removed from the AC. The combined surgery was performed at two separate sites. One site was used for phacoemulsification and the second site for trabeculectomy, where conjunctival dissection at the fornix base was performed prior to cataract surgery with or without mitomycin depending on the case introduced. After cataract surgery, trabeculectomy was performed with flat 10.0 nylon sutures.

After collection, the data were transcribed in Microsoft Excel $^{\circledR}$ software (Microsoft Corporation, Redmond, WA, USA). The Statistical Package for Social Science version 21.0 (IBM Corporation, Armonk, NY, USA) was used to analyze the data.

Categorical variables were presented as absolute value (n) and percentage value (\%). Continuous variables were presented as mean $\pm \mathrm{SD}$ and median $(95 \% \mathrm{CI})$.

The analysis of variance was used to compare the mean age between the combined and isolated cataract surgery groups. The Mann-Whitney test was used to verify the existence of a significant difference between the continuous variables (IOP, axis, pachymetry, ACD, and axial length) as the general mean, the difference between the postoperative and preoperative, and the percent difference in relation to the preoperative period between the combined and isolated cataract groups. In the statistically significant variables, linear regression analysis was used to observe the effect of the variable on the IOP variation in the analyzed groups. The KruskalWallis test was used to test the variables age, IOP 1 month, IOP 3 months, IOP 6 months, IOP 12 months, and the final variation of IOP between the preoperative pressure classes.

For all tests, a 95\% confidence level was considered, that is, $P<0.05$ was considered significant.

\section{Results}

Of the 550 eyes analyzed, 319 did not meet the inclusion criteria of the study or did not present duly completed medical records. Thus, at the end of the data collection, the study consisted of 231 eyes, represented by 179 patients. 
Table I Distribution and comparison of the patients regarding gender and the operated eye in relation to the groups

\begin{tabular}{l|l|l|l}
\hline \multirow{2}{*}{ Variable } & \multicolumn{2}{|l|}{ Cases, $\mathbf{n}(\%)$} & \multirow{2}{*}{-value } \\
\cline { 2 - 3 } & Combined & Cataract & \\
\hline Gender & & & $0.039^{\mathrm{a}}$ \\
Female & $14 / 41.2 \%$ & $88 / 60.7 \%$ & \\
Male & $20 / 58.8 \%$ & $57 / 39.3 \%$ & \\
Total & $34 / 100.0 \%$ & $145 / 100.0 \%$ & \\
Operated eye & & & \multirow{2}{*}{0.977} \\
Right eye & $23 / 46.9 \%$ & $85 / 46.7 \%$ & \\
Left eye & $26 / 53.1 \%$ & $97 / 53.3 \%$ & \\
Total & $49 / 100.0 \%$ & $182 / 100.0 \%$ & \\
\hline
\end{tabular}

Note: Test used: $\chi^{2}$, ${ }^{\text {significant }}(P<0.05)$.

A total of 145 patients undergoing cataract surgery were studied, of which $88(60.7 \%)$ were female and $57(39.3 \%)$ were male, ranging from 46 to 95 years, mean of $72.0 \pm 9.5$ years. Of these, 182 eyes were operated on, 85 on the right side (46.7\%) and 97 on the left side (53.3\%). Regarding combined surgery, 34 patients with a total of 49 eyes participated in the study, 23 on the right side (46.9\%) and 26 on the left side (53.1\%), 14 (41.2\%) of the female gender, and $20(58.8 \%)$ of the male, ranging from 51 to 87 years, with a mean age of $71.9 \pm 8.14$ years (Tables 1 and 2).

In both groups, documented mean IOP was statistically significant in the following periods: preoperative, 24 hours, and 12 months postoperatively (Table 2).

The study analyzed the mean IOP difference during the pre- and postoperative periods of both groups. In the combined surgery, the IOP in the postoperative 24 hours showed a reduction of $9 \mathrm{mmHg}$. Within 30 days after surgery, the IOP difference was close to $7 \mathrm{mmHg}$. And at 12 months

Table 2 Distribution and comparison of patients regarding the variables in relation to the groups

\begin{tabular}{l|l|l|l}
\hline Variable & Combined & Cataract & $P$-value \\
\hline Age $^{\mathrm{a}}$ & $71.9 \pm 8.1$ & $72.0 \pm 9.5$ & $<0.00 \mathrm{I}^{\mathrm{b}}$ \\
IOP before & $18.9 \pm 7.6$ & $15.1 \pm 3.4$ & $0.0 \mathrm{I}^{\mathrm{b}}$ \\
IOP after 24 hours & $8.3 \pm 4.4$ & $15.7 \pm 2.6$ & $<0.00 \mathrm{I}^{\mathrm{b}}$ \\
IOP after 7 days & $13.7 \pm 7.9$ & $15.0 \pm 5.4$ & 0.104 \\
IOP after I5 days & $13.4 \pm 5.3$ & $14.0 \pm 3.3$ & 0.200 \\
IOP after 30 days & $14.5 \pm 6.8$ & $13.0 \pm 2.9$ & 0.592 \\
IOP after 3 months & $12.4 \pm 3.1$ & $11.9 \pm 2.6$ & 0.338 \\
IOP after 6 months & $12.5 \pm 2.9$ & $12.3 \pm 3.2$ & 0.882 \\
IOP after I2 months & $14.4 \pm 4.1$ & $12.6 \pm 2.5$ & $0.042^{\mathrm{b}}$ \\
Axis before & $96.0 \pm 4 I . I$ & $84.4 \pm 4 I .2$ & 0.154 \\
Final axis & $90.9 \pm 36.9$ & $80.2 \pm 43.9$ & $0.21 \mathrm{I}$ \\
Pachymetry & $522.3 \pm 39.2$ & $530.5 \pm 38.6$ & 0.295 \\
ACD & $2.8 \pm 0.3$ & $3.1 \pm 0.3$ & $<0.00 \mathrm{I}^{\mathrm{b}}$ \\
Axial length & $22.9 \pm 0.8$ & $23.3 \pm 1.0$ & $0.014^{\mathrm{b}}$ \\
\hline
\end{tabular}

Notes: Test used: Mann-Whitney, aANOVA, ${ }^{b}$ significant $(P<0.05)$. Data is presented as mean $\pm S D$.

Abbreviations: ACD, anterior chamber depth; IOP, intraocular pressure.

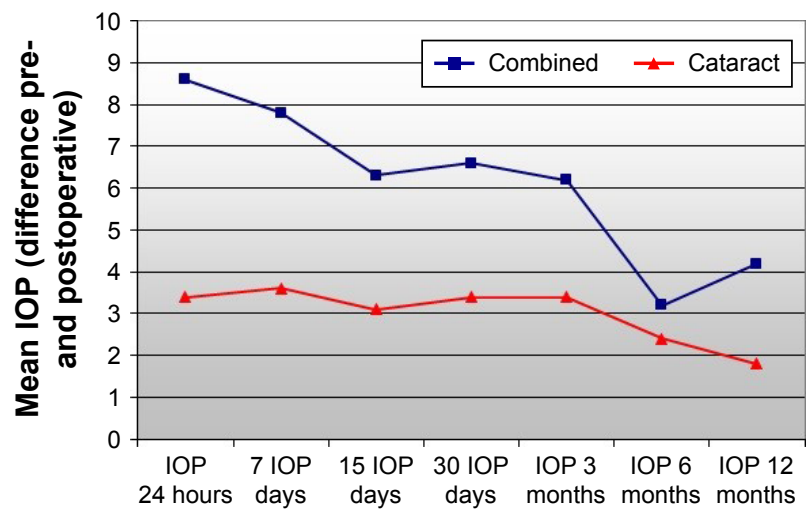

Figure I Mean of IOP difference for pre- and postoperative moments in each group. Abbreviation: IOP, intraocular pressure.

of procedure, the IOP difference reached a value just above $4 \mathrm{mmHg}$. In the isolated cataract surgery, the IOP variation behaved evenly, with values ranging from 3 to $4 \mathrm{mmHg}$ up to 3 months postoperatively and at 12 months postoperative, a value below $2 \mathrm{mmHg}$ (Figure 1).

By correlating the pre- and postoperative values of IOP, a statistical significance of the IOP variation was obtained in the 24-hour, 7-, 15-day, and 12-month periods after surgery. At the end of the study, 12-month follow-up, the IOP variation in combined surgery was $4.2 \pm 2.6 \mathrm{mmHg}$ vs a $1.8 \pm 1.8 \mathrm{mmHg}$ variation in cataract surgery alone (Table 3 ).

In the linear regression analysis of the variables on the pressure difference before and after surgery in the two groups analyzed (Tables 4-7), a discrete influence of the ACD and axial length variables was observed in the immediate postoperative phacoemulsification group (Tables 4 and 5).

It was observed that IOP variation showed a greater reduction in the category where preoperative values were higher (Table 8). Regarding the use of antiglaucomatous drops after 12 months postoperatively, it was observed that $18.4 \%$ of the

Table 3 Distribution and comparison of patients regarding the pre- and postoperative difference in IOP in relation to the groups

\begin{tabular}{l|l|l|l}
\hline Variable & Combined & Cataract & $P$-value \\
\hline Difference (IOP before) & & & \\
IOP after 24 hours & $8.6 \pm 5.9$ & $3.4 \pm 2.3$ & $<0.00 I^{\mathrm{a}}$ \\
IOP after 7 days & $7.8 \pm 7.5$ & $3.6 \pm 3.6$ & $0.015^{\mathrm{a}}$ \\
IOP after I5 days & $6.3 \pm 6.1$ & $3.1 \pm 3.2$ & $0.025^{\mathrm{a}}$ \\
IOP after 30 days & $6.6 \pm 6.3$ & $3.4 \pm 2.3$ & $0.18 \mathrm{I}$ \\
IOP after 3 months & $6.2 \pm 6.2$ & $3.4 \pm 2.5$ & 0.144 \\
IOP after 6 months & $3.2 \pm I .4$ & $2.4 \pm 2.3$ & 0.056 \\
IOP after I2 months & $4.2 \pm 2.6$ & $1.8 \pm 1.8$ & $0.004^{\mathrm{a}}$ \\
\hline
\end{tabular}

Notes: Test used: Mann-Whitney, a ${ }^{a}$ significant $(P<0.05)$. Data is presented as mean \pm SD.

Abbreviation: IOP, intraocular pressure. 
Table 4 Linear regression test between axial length and IOP difference (post - pre) in patients subjected to phacoemulsification

\begin{tabular}{|l|l|l|l|}
\hline Variable & $R^{2}$ & $B$ & $P$-value \\
\hline Difference (IOP before) & 0.08 I & -0.468 & 0.239 \\
\hline IOP after 24 hours & 0.483 & -2.405 & $0.038^{\mathrm{a}}$ \\
\hline IOP after 7 days & 0.108 & -1.047 & $0.058^{\mathrm{a}}$ \\
\hline IOP after I5 days & 0.054 & -0.518 & 0.262 \\
\hline IOP after 30 days & 0.002 & -0.097 & 0.808 \\
\hline IOP after 3 months & 0.149 & 1.108 & 0.113 \\
\hline IOP after 6 months & 0.095 & 0.609 & 0.265 \\
\hline IOP after I2 months
\end{tabular}

Note: $R^{2}=$ coefficient of determination, $B=$ slope of the line, $P=$ statistical significance, asignificant $P<0.05$.

Abbreviation: IOP, intraocular pressure.

patients did not need to use eye drops and $30.4 \%$ used only one class of antiglaucomatous medication (Table 9).

\section{Discussion}

Senile cataract is a disease closely related to aging, its main risk factor. This study showed that women underwent more cataract surgeries when compared to men, possibly due to higher life expectancy, thus being more likely to develop the disease. ${ }^{6}$ Combined surgery, where there is evolutionary glaucoma, has been performed more in men. In the study by Tham et al, ${ }^{7}$ there was a higher prevalence of this disease in males, mainly POAG, which corresponds to the majority of cases. In this particular study, we also found this higher prevalence in the male gender, in accordance with the data in the literature.

In the cataract surgery group alone, up to the sixth postoperative month, IOP declined continuously, but in the 12 months after surgery, this difference was reduced, but did not reach the preoperative values. Considering the statistical

Table 5 Linear regression test between ACD and IOP difference (post - pre) in eyes that were subjected to phacoemulsification

\begin{tabular}{|l|l|l|l|}
\hline Variable & $R^{2}$ & $B$ & $P$-value \\
\hline Difference (IOP before) & 0.565 & -4.184 & $0.001^{\text {a }}$ \\
\hline IOP after 24 hours & 0.163 & -1.654 & 0.370 \\
\hline IOP after 7 days & 0.098 & -2.501 & 0.072 \\
\hline IOP after I5 days & 0.000 & 0.057 & 0.963 \\
\hline IOP after 30 days & 0.006 & 0.618 & 0.718 \\
\hline IOP after 3 months & 0.061 & 1.592 & 0.324 \\
\hline IOP after 6 months & 0.126 & 2.813 & 0.213 \\
\hline IOP after I2 months
\end{tabular}

Note: $R^{2}=$ coefficient of determination, $B=$ slope of the line, $P=$ statistical significance, ${ }^{a}$ significant $P<0.05$.

Abbreviations: $A C D$, anterior chamber depth; IOP, intraocular pressure.
Table 6 Linear regression test between axial length and IOP difference (post-pre) for patients who underwent trabeculectomy with phacoemulsification

\begin{tabular}{|l|l|l|l|}
\hline Variable & $R^{2}$ & B & P-value \\
\hline Difference (IOP before) & 0.008 & -0.967 & 0.666 \\
\hline IOP after 24 hours & 0.027 & -2.104 & 0.445 \\
\hline IOP after 7 days & 0.002 & 0.336 & 0.807 \\
\hline IOP after I5 days & 0.000 & 0.056 & 0.971 \\
\hline IOP after 30 days & 0.030 & I.I88 & 0.491 \\
\hline IOP after 3 months & 0.003 & -0.072 & 0.898 \\
\hline IOP after 6 months & 0.465 & -1.584 & 0.062 \\
\hline IOP after I2 months
\end{tabular}

Note: $R^{2}=$ coefficient of determination, $B=$ slope of the line, $P=$ statistical significance. Abbreviation: IOP, intraocular pressure.

significance in some analyzed variables (Table 2), we tried to perform a linear regression analysis of the pressure difference variables before and after surgery in both groups. It was interesting to note that only in the first 15 days in the phacoemulsification group was an influencing factor observed in the ACD and axial length. We believe that this effect may be related to the immediate postoperative $\mathrm{AC}$ readjustment in this group. The depth of the AC in the preoperative period is smaller when compared to individuals with isolated cataract, which may be related to the metabolic effects secondary to glaucoma interfering in its intumescence leading to a reduction of ACD. The study by Picoto et $\mathrm{al}^{9}$ also showed that although IOP reduction persists after 12-24 months, this negative pressure variation tends to decrease over time. The most significant decrease in IOP seen in the period close to surgery could be explained by the increase in the release of prostaglandin F-2, the effect of which increases drainage of the aqueous humor by the uveoscleral surface. ${ }^{27}$ In combined surgery, a fistula is created on the sclera that can undergo a

Table 7 Linear regression test between ACD and difference in IOP (post - pre) for patients who underwent trabeculectomy with phacoemulsification

\begin{tabular}{|l|l|l|l|}
\hline Variable & $R^{2}$ & B & P-value \\
\hline Difference (IOP before) & 0.006 & -1.979 & 0.703 \\
\hline IOP after 24 hours & 0.017 & -4.146 & 0.538 \\
\hline IOP after 7 days & 0.050 & -3.669 & 0.237 \\
\hline IOP after I5 days & 0.084 & 3.884 & 0.18 I \\
\hline IOP after 30 days & 0.092 & 4.599 & 0.238 \\
\hline IOP after 3 months & 0.061 & -0.999 & 0.594 \\
\hline IOP after 6 months & 0.147 & 1.486 & 0.396 \\
\hline IOP after I2 months
\end{tabular}

Note: $R^{2}=$ coefficient of determination, $B=$ slope of the line, $P=$ statistical significance. Abbreviations: ACD, anterior chamber depth; IOP, intraocular pressure. 
Table 8 Comparison between the means of the variables under study according to preoperative pressure categories for patients who underwent trabeculectomy with phacoemulsification

\begin{tabular}{|c|c|c|c|c|c|}
\hline \multirow[t]{2}{*}{ Variables } & \multicolumn{4}{|c|}{ Mean of preoperative pressure } & \multirow[t]{2}{*}{$P$-value } \\
\hline & $\geq 22 \mathrm{mmHg}$ & I9-2I mmHg & $16-18 \mathrm{mmHg}$ & $6-15 \mathrm{mmHg}$ & \\
\hline Number of eyes & 15 & 5 & 8 & 21 & - \\
\hline Age & $69.1 \pm 8.4$ & $72.9 \pm 9.8$ & $74.9 \pm 6.7$ & $75.7 \pm 6.9$ & 0.178 \\
\hline IOP I month & $11.9 \pm 6.8$ & $17.0 \pm 10.2$ & $20.4 \pm 4.8$ & $13.2 \pm 4.7$ & 0.051 \\
\hline IOP 3 months & $12.0 \pm 3.3$ & $11.6 \pm 4.7$ & $12.3 \pm 1.5$ & $11.8 \pm 2.9$ & 0.675 \\
\hline IOP 6 months & $13.2 \pm 3.9$ & $13.3 \pm 1.5$ & $15.2 \pm 0.5$ & $11.7 \pm 2.5$ & 0.520 \\
\hline IOP I 2 months & $16.0 \pm 6.6$ & $15.0 \pm 5.3$ & $15.0 \pm 1.3$ & $12.9 \pm 3.3$ & 0.251 \\
\hline Final IOP variation with SD & $17.8 \pm 4.0$ & $9.0 \pm 4.6$ & $2.25 \pm 0.5$ & $2.7 \pm 2.1$ & 0.002 \\
\hline
\end{tabular}

Notes: Test used: Kruskal-Wallis. Data is presented as mean \pm SD.

Abbreviation: IOP, intraocular pressure.

fibrotic process, reducing the flow of the aqueous humor that, previously, was facilitated by the same, also leading to the decrease of IOP variation with the passage of time. ${ }^{28}$

The study demonstrated that IOP control was more pronounced in combined surgery than in isolated cataract surgery, probably because both phacoemulsification and trabeculectomy have a distinct ocular hypotensive effect. It is also observed that the ocular antihypertensive effect in those undergoing isolated cataract surgery was more stable when compared to the combined surgery. In the study by Shingleton et $\mathrm{al}^{2}{ }^{29}$ with similar data, it was observed that isolated cataract surgery reduces IOP in a discrete but durable way, independent of glaucoma.

According to Zhang et al,,$^{30}$ on the variation of IOP in patients subjected to combined surgery and isolated cataract surgery, combined surgery had a more significant negative variation than isolated surgery 1 year after the procedure; however, it was not a definitive result because of the lack of statistical significance. This finding corroborates the study in question, which determines a more pronounced IOP decrease when it comes to combined surgery, but in the present study there was statistical relevance of the results.

Combined surgery showed a greater variation in the IOP value; however, the isolated cataract surgery also achieved a significant difference in pre- and postoperative pressures. This reduction of IOP in cataract surgery is probably due

Table 9 Eye distribution regarding the number of classes of antiglaucomatous medications in the pre- and postoperative period for patients who underwent trabeculectomy with phacoemulsification

\begin{tabular}{l|l|l|l|l}
\hline \multirow{2}{*}{$\begin{array}{l}\text { Number of drug } \\
\text { classifications }\end{array}$} & \multicolumn{2}{|l|}{ Preoperative } & \multicolumn{2}{l}{ Postoperative } \\
\cline { 2 - 5 } & $\mathbf{n}$ & $\%$ & $\mathbf{n}$ & $\%$ \\
\hline No medication & 0.0 & 0.0 & 9 & 18.4 \\
One class & 0.0 & 0.0 & 15 & 30.6 \\
Two classes & 6 & 12.2 & 12 & 24.5 \\
Three classes & 37 & 75.6 & 12 & 24.5 \\
Four classes & 6 & 12.2 & $\mathrm{I}$ & 2.0 \\
\hline
\end{tabular}

to two indirect factors that may contribute to facilitate the drainage of the aqueous humor: an increase in the depth of the AC, thus facilitating drainage through the trabecular meshwork,,$^{31,32}$ and the placement of an intraocular lens, which increases the mechanical tension in the zonation region, thus reducing the drainage resistance of the aqueous humor by the expansion of the trabecular meshwork space, but the exact mechanism is still unclear. ${ }^{29,32}$

Due to these factors, isolated cataract surgery may be an important ally for IOP reduction and stability, ${ }^{38,39}$ both in patients with suspected ocular hypertension and in those with controlled glaucoma with antiglaucoma medication, even in cases of suspected angular closure. In the cases of POAG, the hypotensive effect of the isolated surgery is smaller, because the cause of this pathology is a dysfunction of the trabecular meshwork, but even with this lower reduction, surgery is already able to improve the pressure control. However, in patients that require more rigorous IOP control, isolated surgery does not present as an effective reduction as trabeculectomy. Combined surgery may be used in some situations in which the diseases coexist and a marked reduction of IOP is required. ${ }^{33}$

This behavior of pressure variation evidenced in the study can occur in both normal eyes and hypertensive and/or glaucomatous eyes; however, those with higher preoperative IOP show a more significant reduction. We observed that the postoperative variability was more evident in the combined surgery when compared to isolated cataract surgery after 12 months postoperation (mean of $23.8 \% \times 16.5 \%$ ) in the final reduction. In addition, the effect of the decreased IOP was more pronounced in elderly female patients with shortened axial length. ${ }^{34}$

The coexistence of cataract and glaucoma is common in people with advanced age, increasing progressively starting in the $60 \mathrm{~s}$. The decision of a patient with glaucoma and cataract to undergo either isolated cataract surgery or 
combined surgery is quite complex, and several factors may influence this choice, such as the fact that trabeculectomy can accelerate the progression of cataracts; phacoemulsification, by itself, already produces a hypotensive effect; a cataract surgery following glaucoma surgery may compromise IOP control; among others. ${ }^{30}$ It is recommended that the professional analyze each case individually, aiming to maximize the proposed treatment, making it more effective, durable, and safe for the patient.

Regarding combined surgery, the study by Mandia Jr Carmo compared long-term IOP control after extracapsular facectomy combined with trabeculectomy with phacotrabeculectomy. It has been shown that in both groups these two surgical options are safe and effective for the simultaneous treatment of cataract and glaucoma. However, among the combined surgeries, phacotrabeculectomy leads to better IOP control without associated medication, due to a technique using a smaller incision, closer to a trabeculectomy, and having a reduced inflammatory reaction..$^{35}$

In this particular study, we observed that IOP reductions were higher in the IOP group with more elevated pressure (Table 8). It is very interesting to observe that in the excellent work of Poley et al, ${ }^{38}$ they analyzed that in eyes with glaucoma undergoing cataract surgery, a greater reduction in this same category was presented. We observed that the reducing effect of IOP was more evident in the combined surgery group, possibly due to the additive effect of trabeculectomy, and this may be an important ally in cases of decompensated or progressing glaucoma, where a higher value of IOP is desired. The analysis showed that $18.4 \%$ of the patients after 12 months postoperation did not require ocular antihypertensive eye drops and $30.6 \%$ used only one class of medication to better control IOP (Table 9). With this, combined surgery may also have a further additive effect with reducing costs with ocular antihypertensive medications, with the consequent improvement in patients' quality of life and financial status. ${ }^{39}$ We must emphasize that when choosing the surgical technique to be employed, the ophthalmologist should individualize their choice according to the clinical case of the patient, prioritizing the safety, efficacy, and postoperative quality of life of this particular patient. ${ }^{40,41}$

In the present study, using the pneumatic tonometer, it was evidenced that the IOP values were significantly reduced after isolated cataract surgery and combined surgery in the short and medium term, when compared with the preoperative measurements. Some studies ${ }^{36,37}$ have already shown a reduction in IOP in a short period of time in isolated cataract, as well as a good concordance between the calibration of pneumatic tonometry and Goldmann's applanation tonometry. We believe that in the near future, with technological improvement, new studies will be able to analyze this pressure behavior with better accuracy, in relation to the measurement of IOP through pneumatic tonometry.

\section{Conclusion}

The authors observed that IOP reduction when measured in pneumatic tonometry in both surgical approaches was more significant in the combined surgery group. It was also evidenced that the isolated cataract surgery presented a uniform and less variable reduction when compared with the combined surgery.

We must emphasize the limitations of this study. The limited number of patients, the noncomparison of IOP found with noncontact tonometer and Goldman's applanation tonometry, as well as if both IOP measurement techniques had some degree of influence on the studied variables could all be important limiting factors of this study. A proposal for future research would be to conduct longitudinal, doubleblind, and randomized studies to observe the reproducibility of IOP gauging measurements through the use of pneumatic tonometry and Goldmann applanation.

\section{Acknowledgments}

We thank the Pontifical Catholic University of Goiás for providing the opportunity to carry out this research project, Hospital Ver, for all openings granted to us during the data collection of the study, and the secretaries, Rosângela Santos and Ana Caroline Brandão, for their solidarity and proactivity, always available to give us assistance during the tabulation period of the medical records information.

\section{Disclosure}

The authors report no conflicts of interest in this work.

\section{References}

1. Conselho Brasileiro de Oftalmologia. Diretriz - Catarata: diagnóstico e tratamento. [Guideline - Cataract: diagnosis and treatment]; 2003. Available from: http://www.cbo.com.br/novo/medico/pdf/Diretrizes_ CBO_AMB_CFM.pdf. Accessed September 21, 2018. Portuguese.

2. European Glaucoma Society Terminology and Guidelines for Glaucoma, 4th Edition-Chapter 2: Classification and terminologySupported by the EGS Foundation: Part 1: Foreword; Introduction; Glossary; Chapter 2 Classification and Terminology. Br J Ophthalmol. 2017;101(5):73.

3. Snellingen T, Evans JR, Ravilla T, Foster A. Surgical interventions for age-related cataract. Cochrane Database Syst Rev. 2002;2(2)CD001323: CD001323.

4. Taleb A, Ávila M, Moreira H. As Condições de Saúde Ocular no Brasil [The Ocular Health Conditions in Brazil]. São Paulo: International Standard Book; 2009. Portuguese.

5. Kara-Junior N, Santhiago MR, Parede TR, et al. Influence of cataract surgical correction on working perception. Arq Bras Oftalmol. 2010;73(6): 491-493. Portuguese.

6. Medina NH, Muños EH. Atenção saúde ocular da pessoa idosa [Eye care of the elderly]. Bepa. 2011;8(85):23-28. Portuguese. 
7. Tham YC, Li X, Wong TY, Quigley HA, Aung T, Cheng CY. Global prevalence of glaucoma and projections of glaucoma burden through 2040: a systematic review and meta-analysis. Ophthalmology. 2014; 121(11):2081-2090.

8. Ferreira JM, Cavalcanti MLH. Catarata: evolução do tratamento cirúrgico. [Cataract: evolution of surgical treatment]. In: Anais da XXVII Jornada do Internato do Curso de Medicina; UNIFESO; 2016 [Proceedings of the XXVII Internship Medicine Course; UNIFESO; 2016]; 2016. Available from: http://filoinfo.net/portalunifesopublicacoeseletronicas/sites/default/files/xxvii_jornada_medicina_0.pdf. Accessed September 21, 2018. Portuguese.

9. Picoto M, Galveia J, Almeida A, et al. Pressão intraocular (PIO) após cirurgia de extração de catarata [Intraocular pressure (IOP) after cataract extraction surgery]. Rev Bras Oftalmol. 2014;73(4):230-236. Portuguese.

10. Azuara-Blanco A, Burr J, Ramsay C, et al. Effectiveness of early lens extraction for the treatment of primary angle-closure glaucoma (EAGLE): a randomised controlled trial. Lancet. 2016;388(10052):1389-1397.

11. Ministério da Saúde. Portaria $n^{\circ} 1279$, de 19 de novembro de 2013 Aprova o Protocolo Clínico e Diretrizes Terapêuticas do Glaucoma [Clinical protocol and therapeutic guidelines. Ordinance number 1279, 19 November 2013]; 2013. Available from: http://portalarquivos.saude. gov.br/images/pdf/2014/abril/02/pcdt-glaucoma-2013.pdf. Accessed September 21, 2018. Portuguese.

12. Guedes RAP. A esclerectomia profunda não penetrante como forma da prevenção da cegueira pelo glaucoma e seu impacto na saúde coletiva: um estudo de custo-efetividade. 2008. $62 f$ [Deep non-penetrating sclerectomy as a form of prevention of glaucoma blindness and its impact on collective health: a cost-effectiveness study. 2008. 62f.]. Dissertação (Mestrado em Saúde Coletiva) - Faculdade de Medicina, Universidade Federal de Juiz de Fora, Juiz de Fora; 2008. Available from: https://repositorio.ufjf.br/jspui/bitstream/ufjf/2864/1/ricardoaugustopalettaguedes.pdf. Accessed June 06, 2018. Portuguese.

13. Susanna R Jr, Andrade Medeiros F, Hatanaka M. Tratamento cirúrgico do glaucoma [Glaucoma treatment surgery]; 2017. Available from: www.moreirajr.com.br/revistas.asp?fase $=$ r003\&id_materia $=2017$. Accessed September 21, 2018. Portuguese.

14. Palmberg PF. The role of IOP in the success or failure of medical and/or surgical therapy. Preferred Practice Patten for Primary Open-Angle Glaucoma, Appendix I. San Francisco, CA: American Academy of Ophthalmology; 1992.

15. International Glaucoma Association. The charity for people with glaucoma established since 1974. Trabeculectomy. Ashford, UK: International Glaucoma Association; 2015. Available from: https:// www.glaucoma-association.com/media/wysiwyg/Leaflet_PDF_Files/ Trabeculectomy.pdf. Accessed June 06, 2018.

16. Marchini G, Ceruti P, Vizzari G, Berzaghi D, Zampieri A. Management of concomitant cataract and glaucoma. In: Bettin P, Khaw PT, editors. Glaucoma Surgery. 2nd ed. Vol 59. Basel: Karger; 2017:155-164.

17. Yanoff M, Duker JS. Oftalmologia. 3rd ed. London: Elsevier; 2011.

18. Lopes-Cardoso I. Cirurgia de glaucoma associado a catarata: cirurgia combinada ou sequencial? [Glaucoma surgery associated with cataracts: surgery combined or sequentially?] Available from: http://glaucomaanswers.org/pt-pt/inicio/terapeutica-cirurgica/cirurgia-glaucomaassociado-catarata. Accessed September 21, 2018. Portuguese.

19. Tham CC, Kwong YY, Leung DY, et al. Phacoemulsification vs phacotrabeculectomy in chronic angle-closure glaucoma with cataract: complications [corrected]. Arch Ophthalmol. 2010;128(3):303-311.

20. Grolman B. A new tonometer system. Am J Optom Arch Am Acad Optom. 1972;49(8):646-660.
21. Estrada EI. Estudo comparativo entre o tonometro de aplanacao de goldmann e o tonometro de nao contacto em pacientes com glaucoma primario de angulo aberto [Comparative study between the aplanation tonometer of goldmann and the non-contact tonometer in patients with primary open angle glaucoma] Available from: https://repositorio.ipl. pt/bitstream/10400.21/4229/1/Estudo\%20comparativo\%20entre $\% 20$ o\%20TAG\%20e $\% 20$ o $\% 20$ TNC $\% 20 \mathrm{em} \% 20$ pacientes $\% 20$ com $\% 20$ GPAA.pdf. Accessed June 6, 2018. Portuguese.

22. Britt JM, Clifton BC, Barnebey HS, Mills RP. Microaerosol formation in noncontact 'air-puff' tonometry. Arch Ophthalmol. 1991;109(2): 225-228.

23. Recep OF, Hasiripi H, Cağil N, Sarikatipoğlu H. Relation between corneal thickness and intraocular pressure measurement by noncontact and applanation tonometry. J Cataract Refract Surg. 2001;27(11): 1787-1791.

24. Caiado RR, Badaró E, Kasahara N. Intraocular pressure fluctuation in healthy and glaucomatous eyes: a comparative analysis between diurnal curves in supine and sitting positions and the water drinking test. Arq Bras Oftalmol. 2014;77(5):288-292.

25. Schimiti RB, Costa VP. Perimetria Computadorizada [Computerized Perimetry]. 4th ed. Rio de Janeiro: Cultura Médica; 2017. Portuguese.

26. Anderson D. Automated Static Perimetry. St Louis: Mosby-Year Book; 1992.

27. Mathalone N, Hyams M, Neiman S, Buckman G, Hod Y, Geyer O. Long-term intraocular pressure control after clear corneal phacoemulsification in glaucoma patients. J Cataract Refract Surg. 2005;31(3): 479-483.

28. Mello E Oliveira Nde, Porto RB, Freitas TG, Lacava AC. Estudo comparativo entre a eficácia da trabeculectomia com e sem uso de 5-Fluorouracil ou Mitomicina-C [Comparative study between the efficacy of trabeculectomy with and without the use of 5-Fluorouracil or Mitomycin-C]. Arq Bras Oftalmol. 1999;62(6):739-746. Portuguese.

29. Shingleton BJ, Pasternack JJ, Hung JW, O’Donoghue MW. Three and five year changes in intraocular pressures after clear corneal phacoemulsification in open angle glaucoma patients, glaucoma suspects, and normal patients. J Glaucoma. 2006;15(6):494-498.

30. Zhang ML, Hirunyachote P, Jampel H. Combined surgery versus cataract surgery alone for eyes with cataract and glaucoma. Cochrane Database Syst Rev. 2015;7:CD008671.

31. Poley BJ, Lindstrom RL, Samuelson TW. Long-term effects of phacoemulsification with intraocular lens implantation in normotensive and ocular hypertensive eyes. $J$ Cataract Refract Surg. 2008;34(5): 735-742.

32. Shrivastava A, Singh K. The effect of cataract extraction on intraocular pressure. Curr Opin Ophthalmol. 2010;21(2):118-122.

33. Melancia D, Abegão Pinto L, Marques-Neves C, Pinto LA, Neves CM. Cataract surgery and intraocular pressure. Ophthalmic Res. 2015;53(3): 141-148.

34. Zetterström C, Behndig A, Kugelberg M, Montan P, Lundström M. Changes in intraocular pressure after cataract surgery: analysis of the Swedish National Cataract Register Data. J Cataract Refract Surg. 2015; 41(8):1725-1729.

35. Mandia C Jr, Kasahara N, Seixas FS, Paolera MD, Almeida GVD, Cohen R. Comparação a longo prazo entre a facectomia extracapsular combinada à trabeculectomia e à facotrabeculectomia [Long-term comparison between extracapsular facectomy combined with trabeculectomy and phacotrabeculectomy]. Arq Bras Oftalmol. 2002;65(6):641-644. Portuguese. 
36. da Silva RE, de Sousa Paiva IC, de Souza JF, Wellington Rodrigues F. Comportamento da pressão intraocular no tonômetro de aplanação de Goldmann e pneumático durante o teste de sobrecarga hídrica [Intraocular Pressure Behavior in the Goldmann and Pneumatic Tonometer during Water Drinking Test]. Rev Bras Oftalmologia. 2018;77(1):14-19. Accessed May 24, 2018. http://www.scielo.br/ scielo.php?script=sci_arttext\&pid=S0034-72802018000100014\&lng=en\&nrm=iso. Portuguese.

37. Rodrigues FW, Silva CM, Modesto DC, de Oliveira AW, da Silva RE. Intraocular pressure variation by pneumatic tonometer before and after phacoemulsification. Eur J Ophthalmol. 2018;28(4):393-397. Epub 2018 Mar 15.

38. Poley BJ, Lindstrom RL, Samuelson TW, Schulze R. Intraocular pressure reduction after phacoemulsification with intraocular lens implantation in glaucomatous andnonglaucomatous eyes. Journal of Cataract \& Refractive Surgery. 2009;35(11):1946-1955.
39. Chan PP, Li EY, Tsoi KKF, Kwong YY, Tham CC. Cost-effectiveness of phacoemulsification versus combined phacotrabeculectomy for treating primary angle closure glaucoma. J Glaucoma. 2017;26(10): 911-922.

40. Kim KS, Kim JM, Park KH, Choi CY, Chang HR. The effect of cataract surgery on diurnal intraocular pressure fluctuation. J Glaucoma. 2009;18(5):399-402.

41. Bojikian KD, Chen PP. Intraocular pressure after phacoemulsification in open angle glaucoma patients with uncontrolled or marginally controlled glaucoma and/or with severe visual field loss. J Glaucoma. 2018;27(2):1-14.
Clinical Ophthalmology

\section{Publish your work in this journal}

Clinical Ophthalmology is an international, peer-reviewed journal covering all subspecialties within ophthalmology. Key topics include: Optometry; Visual science; Pharmacology and drug therapy in eye diseases; Basic Sciences; Primary and Secondary eye care; Patient Safety and Quality of Care Improvements. This journal is indexed on

Submit your manuscript here: http://www.dovepress.com/clinical-ophthalmology-journal

\section{Dovepress}

PubMed Central and CAS, and is the official journal of The Society of Clinical Ophthalmology (SCO). The manuscript management system is completely online and includes a very quick and fair peer-review system, which is all easy to use. Visit http://www.dovepress.com/ testimonials.php to read real quotes from published authors. 